\title{
Models of analysis and forecasting of the traffic situation
}

\author{
Yaroslav I. Shamlitskiy ${ }^{l}$, Daria V. Rogova ${ }^{l}$, Anastasiya S. Polyakova ${ }^{1}$, Anatoly A. Popov ${ }^{l}$ and \\ Leonid V. Lipinskiy ${ }^{l}$ \\ ${ }^{1}$ Reshetnev Siberian State University of Science and Technology, 31, Krasnoyarskiy rabochiy pr., Krasnoyarsk, \\ 660037, Russia
}

\begin{abstract}
The article discusses the results of the analysis of methods and models for predicting road safety. The problem of creating mathematical models and software for describing and analyzing traffic processes is very relevant. The analysis of the study of road traffic accidents is given and the cause-and-effect relationships of road traffic and the conditions for the occurrence of problem situations are established. The task of developing a methodology for predicting and preventing road accidents with the aim of reducing road accidents is being solved. An example of a simulation model that describes the route network of a city is given. A computer experiment was able to trace the congestion of sections of the road network. This work is devoted to solving a number of problems associated with this problem, aimed at improving the quality of the city's transport system by reducing the likelihood of an accident and eliminating the downtime of route vehicles due to congestion and traffic jams, and also contributes to the timely delivery of passengers to a certain destination. With the help of the developed model, it is possible to study bottlenecks of transport services, assess the traffic situation, reduce tension and the number of accidents on the roads, improve the environmental situation, identify further directions of development and improvement.
\end{abstract}

\section{Keywords}

Traffic situation, road traffic, mathematical models, simulation traffic

\section{Introduction}

Today, improving the level of road safety, as well as preserving the life and health of citizens is one of the main priority directions of the state policy of the Russian Federation and an important indicator of ensuring socio-economic and demographic development [1-3].

For the medium-term planning period, the basis of this policy is the Road Safety Strategy in the Russian Federation for 2018 - 2024 (Strategy), approved by the order of the Government of the Russian Federation dated January 08, 2018 No. 1-r. The main goal of the Strategy is to strive for zero mortality rates on the roads by 2030, and the target for 2024 is the level of social risk, which is no more than 4 deaths as a result of road traffic accidents per 100 thousand population [4- 6].

According to the data provided in the Strategy, road accidents caused colossal social, material and demographic damage to the Russian economy. 2007 to 2016271 thousand people died in road accidents, 2.5 million people were injured. More than $30 \%$ of those killed in road accidents are citizens of active working age (26-40 years), $20 \%$ of the victims remain disabled. Every year, the economic losses of the state from road accidents amount to about $2 \%$ of the gross domestic product [7-9].

III International Workshop on Modeling, Information Processing and Computing (MIP: Computing-2021), May 28, 2021, Krasnoyarsk, Russia

EMAIL: 2538357@mail.ru (Yaroslav Shamlitskiy); dasha_28_05@mail.ru (Daria Rogova); polyakova_nasty@mail.ru (Anastasiya Polyakova); tolynbms@yandex.ru (Anatoly Popov); lipinskiyl@̄mail.ru (Leonid Lipinskiy)

ORCID: 0000-0002-9030-8388 (Yaroslav Shamlitskiy); 0000-0003-4765-6069 (Daria Rogova); 0000-0003-1035-4403 (Anastasiya Polyakova); 0000-0002-9361-1825 (Anatoly Popov); 0000-0002-7833-8656 (Leonid Lipinskiy)

(c) (i) 2021 Copyright for this paper by its authors.

Use permitted under Creative Commons License Attribution 4.0 International (CC BY 4.0).

CEUR Workshop Proceedings (CEUR-WS.org) 
An increase in the number of private vehicles and an increase in the intensity of commercial freight and passenger traffic requires constant work to ensure road safety, reduce the number of accidents and eliminate the places of concentration of accidents [10-12].

The priority areas specified in the Strategy include:

- Changing the behavior of road users, aimed at unconditional compliance with the rules and regulations

- Increasing the protection from road accidents and their consequences for the most vulnerable road users, especially children and pedestrians

- Improvement of the road network in terms of road safety, including the development of work on the organization of road traffic

- Improvement of organizational and legal mechanisms for admitting vehicles and their drivers to participate in road traffic

- Improvement of the road safety management system - development of the system of assistance and rescue of victims of road accidents

The object of the research is road traffic accidents, and the subject of the research is the cause-andeffect relationship of road traffic and the conditions for the occurrence of an accident.

To implement the directions identified in the Strategy, along with practical measures, scientific research is required.

The relevance of this problem, which is of great socio-economic importance, as well as its theoretical and practical significance, predetermined the choice of the topic, the formulation of the goals and objectives of the study.

The need to reduce road traffic deaths as a result of road accidents leads to the need for the development and improvement of scientific and methodological approaches to predicting and preventing road traffic accidents.

The main task in this work is to develop a methodology for predicting and preventing road traffic accidents in order to reduce road accidents.

\section{Methods for determining road safety}

Computer programs are capable of performing complex calculations during the examination of an accident without increasing the duration of the examination. The use of electronic computers in the investigation of road accidents is not something new. Since 1964, the All-Russian Scientific Research Institute of Forensic Expertise has introduced into expert practice the program "Autoex" program into expert practice, designed to study pedestrian collisions [1]. The third version of the program "Autoex3 " is capable of solving 14 most common questions: eight concerning a collision with a pedestrian with unlimited visibility and visibility; the other six - with visibility limited by the car (moving or stationary) $[1,3]$. The program in its calculations is based on a formatted model of expert research of collisions. In total, "Autoex-3" provides for the input of over 40 initial data. For most quantitative data, up to 4 variants of numerical values are provided, and for qualitative data - up to 10. The expert was required first of all to study the initial data, and then encode them and enter them into a special coding form, consisting of two columns: a list of encoded data and a set code.

Another system, "Collision Analysis", was developed at the Moscow Automobile and Highway State Technical University. Its main feature is that it is universal for any type of collision. When calculating for each collision, its own program is used, and the machine gives only the results of calculations and conclusions. This system was further developed in the form of the Expert Analysis application package. Here, an interactive mode of operation already took place: the program sequentially required the expert to enter the corresponding initial data from the keyboard. At the end of the input, the system draws up the input data in the form of tables and displays it on the monitor so that the expert can check their correctness. Then the entered data is accepted for calculation, which occurs in several stages, depending on the algorithm. At the end of the calculation process, the machine displays the calculation results and outputs on the screen or, if necessary, prints out.

There is one more system "Expertise-4" based on the analog computing device MN-10. The main difference between analog and digital computers is that in this device data is represented in the form of analog physical quantities that are continuously changing over time. Each device is designed according 
to a specific scheme in accordance with the tasks it solves. The "Expertise-4" system is designed to investigate pedestrian collisions and collisions. There are various programmable calculators that are easy to use but don't have as much computing power. A comprehensive analysis of existing methods for analyzing road safety indicators is reflected in the work of L S Abramova [13].

According to the analysis of the sectoral regulatory document, a system of coefficients is used to assess the rate of accident rate of a road section:

Relative accident rate:

- For long and uniform sections of roads (highways) [9]:

$$
U=\frac{\mathrm{z} 10^{6}}{\mathrm{TLN}}, \text { Accidents per } 1 \text { million auto }-\mathrm{km} \text {. }
$$

where $\mathrm{z}$ - is the number of accidents during the time period $\mathrm{T} ; \mathrm{T}$ - time period, [days]; $\mathrm{N}$ - the average annual traffic intensity (average over the time period T), [auto/day]; $\mathrm{L}$ is the length of the road section, $[\mathrm{m}]$.

- For short sections of roads (intersections, junctions, etc.) [9]:

$$
U=\frac{\mathrm{z} 10^{6}}{\mathrm{~T} \mathrm{~N}} \text {, Traffic accidents for } 1 \text { million vehicles. }
$$

The next method, which can also be attributed to the method of statistical processing of road accident data, is a method that allows you to determine the danger of a road section [9]:

$$
V_{0}=p_{0} n_{0}+p_{1} n_{1}+p_{2} n_{2}+p_{3} n_{3}
$$

where $v_{0}$ - hazard indicator; $p_{0}, \ldots, p_{3}$ - conditional accident severity factors; $n_{0}, \ldots, n_{3}$ - the number of road accidents with material damage, minor injury, severe injury and death of people, respectively.

The value of the hazard $V_{0}^{\prime}$ for the highway, taking into account the value of the average daily intensity, is calculated by the formula [6]:

$$
V_{0}^{\prime}=\frac{\sum p_{i} n_{i}}{365 l N_{a}}
$$

where $V_{0}^{\prime}$ - hazard indicator; $p_{i}$ - severity coefficient of road accidents in this group; $n_{i}$ - number of accidents in this group; $l$-highway length, [m].; $N_{a}$-average daily traffic intensity.

The second group includes methods for determining the parameters of the conditions and modes of movement of vehicles:

- $\quad$ Safety factor method [6]:

$$
k_{\text {safe }}=\frac{V_{\text {max }}}{V_{\text {enter }}}
$$

where $V_{\max }$ - is the maximum speed of movement in the area under consideration; $V_{\text {enter }}$ - the maximum speed of vehicles entering the area under consideration.

- Method of accident rates [6]:

$$
K_{\text {rates }}=\prod_{i=1}^{n} K_{i}
$$

where $K_{i}$ - partial accident rates, determined from the analysis of statistical data on road accidents and characterizing the impact on traffic safety of road and street parameters, infrastructure elements, traffic intensity, coverage condition; $i=[1, \ldots, n]-$ the number of partial accident rates taken into account when assessing traffic safety on roads or city streets of various categories.

The third group includes methods for analyzing conflict situations:

- $\quad$ Method of "conflict situations" [5, 11]:

$$
K_{C S}=0.44 K_{1}+0.83 K_{2}+K_{3}
$$

where $K_{c s}$ - critical number of conflict situations; $K_{l}, K_{2}, K_{3}$ - the degree of the conflict situation, respectively, light, medium and critical.

- Method for assessing the danger of a conflict point [11]:

$$
q_{i}=K_{i} M_{i} N_{i} \frac{25}{K_{r}} 10^{-7},
$$

where $q_{i}$ - danger of conflict point; $K_{i}$ - the relative accident rate of the conflict point; $M_{i}$ и $N_{i}$ - traffic intensity on the main and secondary roads, respectively, intersecting flows at a given conflict point, [auto/day]; $K_{r}$ - coefficient of annual unevenness of movement; a factor of 25 has been introduced into the formula to take into account the average number of working days in a month during which the road load sharply exceeds the load on non-working days.

- Method for assessing the danger of a conflict point (traffic safety indicator) [11, 12]: 


$$
K_{\mathrm{a}}=\frac{G 10^{7} K_{r}}{(M+N) 25^{\prime}}
$$

where $K_{a}$ - traffic safety indicator characterizing the number of accidents per 10 million vehicles passing through the intersection; $G=\sum_{i=1}^{n} q_{i}$ - theoretically probable number of accidents at the intersection in 1 year; $n$-is the number of conflict points at the intersection; $M$ - is the intensity on the main road, [auto/day]; $N$ - the same for the secondary road.

- Method of conflict points (Rappoport method). The intersection difficulty index is determined by the formula [9]:

$$
m=n_{0}+3 n_{c}+5 n_{n}
$$

where $n_{0}, n_{c}, n_{n}$ - the number of points, respectively, of deviation (branching), merging and intersection.

- Methodology for assessing the indicator of conflict (Schnabel - Lohse method). The value of the $G_{n}$ index is calculated by the formula [10]:

$$
G_{n}=\sum_{i=1}^{n} K_{0} G_{i}
$$

where $G_{i}=\frac{K_{0} M_{\min }}{10^{4}}$ conflict index for the $i$-th conflict point.

The next group of methods are methods based on the analysis of driver behavior:

- Analysis of deviations from the normal behavior of road users. The essence of this method lies in the analysis of the complex psychological interaction between the driver and the driving conditions [11-13].

- Driver testing method. This method is based on comparing the deviation of the relative heart rate from the normal value [13]:

$$
F=\frac{f-f_{0}}{f} \cdot 100,
$$

where $f$-normal heart rate; $f_{0}$ - heart rate when driving conditions change.

The last group of methods are methods based on the definition of a complex road safety:

- The qualimetric method, first proposed by Professor Sidenko V.M., is based on determining a set of factors - technical, ergonomic and economic [13]:

$$
K_{R S}=K_{T}+K_{E R}+K_{E C}
$$

where $K_{T}, K_{E R}, K_{E C}$ - technical, ergonomic and economic factors.

- A complex approach [11]:

$$
F=D-S \rightarrow \min ,
$$

where $D$ - total losses of society from road traffic accidents; $S$ - the cost of work.

Based on the results of the analysis of existing works in the field of road safety assessment analysis methods, it is possible to determine the main advantages and disadvantages of each considered method presented in the Table 1 [13].

\section{Table 1}

The results of the analysis of methods for determining road safety based on the research results of $L$ S Abramova

\begin{tabular}{cccc}
\hline Method & Model type & Advantages & Disadvantages \\
\hline $\begin{array}{c}\text { Relative accident } \\
\text { rate (on the highway } \\
\text { section) Relative } \\
\text { accident rate (at the } \\
\text { local site) }\end{array}$ & $U=\frac{\mathrm{z} 10^{6}}{\mathrm{TLN}}$ & $\begin{array}{c}\text { This method makes it } \\
\text { possible to determine } \\
\text { comparable data in } \\
\text { the analysis of road } \\
\text { safety }\end{array}$ & $\begin{array}{c}\text { Assumes the } \\
\text { availability of statistical } \\
\text { data on road accidents } \\
\text { for at least 3-5 years }\end{array}$ \\
$\begin{array}{c}\text { Relative accident } \\
\text { rate (on the highway } \\
\text { section) Relative } \\
\text { accident rate (at the } \\
\text { local site) }\end{array}$ & $U=\frac{\mathrm{z}^{\prime} 10^{6}}{\mathrm{TN}}$ & & \\
\end{tabular}




\begin{tabular}{|c|c|}
\hline Reingold method & $\begin{array}{l}V_{0}=p_{0} n_{0}+ \\
+p_{1} n_{1}+ \\
+p_{2} n_{2}+p_{3} n_{3}\end{array}$ \\
\hline $\begin{array}{l}\text { Conflict point } \\
\text { method }\end{array}$ & $\begin{array}{l}\text { Five-point rating } \\
\text { system } m=n_{0}+ \\
\quad 3 n_{c}+5 n_{n}\end{array}$ \\
\hline & $\begin{array}{l}\text { Ten-point grading } \\
\text { system }\end{array}$ \\
\hline $\begin{array}{l}\text { Methodology for } \\
\text { assessing the } \\
\text { indicator of conflict }\end{array}$ & $G_{n}=\sum_{i=1}^{n} K_{0} G_{i}$ \\
\hline $\begin{array}{l}\text { Conflict point hazard } \\
\text { assessment method }\end{array}$ & $q_{i}=K_{i} M_{i} N_{i} \frac{25}{K_{r}} 10^{-7}$ \\
\hline Conflict method & $\begin{array}{l}K_{C S}=0.44 K_{1}+ \\
+0.83 K_{2}+K_{3}\end{array}$ \\
\hline $\begin{array}{c}\text { Analysis of } \\
\text { deviations from the } \\
\text { normal behavior of } \\
\text { road users }\end{array}$ & $\begin{array}{l}\text { The method consists in } \\
\text { analyzing the complex } \\
\text { psychological } \\
\text { interaction between } \\
\text { the driver and the } \\
\text { driving conditions. }\end{array}$ \\
\hline $\begin{array}{l}\text { Driver testing } \\
\text { method }\end{array}$ & $F=\frac{f-f_{0}}{f} \cdot 100$ \\
\hline
\end{tabular}

Taking into account the severity of individual accidents

Allows you to evaluate various traffic patterns

More detailed assessment of the conflict with the ability to take into account the trajectory and the angle of rotation It takes into account only the minimum intensity of the conflicting flows and the hazard coefficient of the implementation of a separate maneuver

Takes into account the danger of a conflict point, depending on many parameters

Allows to take into account the change in speed or trajectory of the vehicle, longitudinal and lateral accelerations

The analysis of the behavior of the road user is carried out according to 40 criteria of driving quality

Takes into account a large number of factors affecting road safety
Does not allow to take into account the characteristics of the traffic flow, in particular the traffic intensity Does not allow assessing the complexity of the traffic junction due to the fact that the traffic intensity is not taken into account

Does not allow assessing the danger of a maneuver and the danger of a network section

The complexity of accounting for a large amount of data due to the large amount of resources involved vehicle detectors, a laboratory car, etc.

Allows to evaluate only one element (driver) does not correspond to the comprehensive assessment of road safety

Labor intensity in the selection of subjects

Does not display the peculiarities of traffic

flow in urban conditions and on 


\begin{tabular}{|c|c|c|c|}
\hline & & & $\begin{array}{l}\text { roads outside } \\
\text { settlements }\end{array}$ \\
\hline Complex method & $F=D-S \rightarrow \min$ & $\begin{array}{l}\text { Determination and } \\
\text { management of road } \\
\text { safety levels on the } \\
\text { road network is } \\
\text { carried out taking into } \\
\text { account the macro } \\
\text { and microeconomic } \\
\text { indicators of the } \\
\text { region }\end{array}$ & $\begin{array}{l}\text { The accident rate is } \\
\text { determined according } \\
\text { to the indicators of the } \\
\text { first group, which does } \\
\text { not allow for a } \\
\text { comprehensive } \\
\text { assessment }\end{array}$ \\
\hline Safety factor method & $k_{\text {safe }}=\frac{V_{\text {max }}}{V_{\text {enter }}}$ & $\begin{array}{l}\text { Evaluates low- } \\
\text { intensity or peak-to- } \\
\text { peak areas in more } \\
\text { congested areas }\end{array}$ & $\begin{array}{c}\text { Speed limits according } \\
\text { to traffic rules are not } \\
\text { taken into account }\end{array}$ \\
\hline $\begin{array}{c}\text { Accident rate } \\
\text { method }\end{array}$ & $K_{\text {rates }}=\prod_{i=1}^{n} K_{i}$ & $\begin{array}{l}\text { Has a wide practical } \\
\text { application in } \\
\text { assessing the impact } \\
\text { of traffic conditions on } \\
\text { road safety }\end{array}$ & $\begin{array}{l}\text { They do not allow to } \\
\text { take into account } \\
\text { changes in the } \\
\text { parameters of traffic } \\
\text { conditions and } \\
\text { methods of organizing } \\
\text { traffic }\end{array}$ \\
\hline
\end{tabular}

\section{Simulation model of the experiment}

As an example of a simulation model, we will consider the route network of the city and an experiment on the model of a computer experiment.

The essence of the simulation experiment on the model is that minibuses of different types, with different speeds and different capacities, leaving at a given time interval on the line, move along routes from one stopping point to another, stop in them, drop passengers and pick up people from stops. The appearance of people at stops is also set according to a certain law, depending on the time of day.

The model allows you to fix the number of route vehicles on each stretch (road section between stopping points) at each moment of time. The degree of congestion of the sections of the city's route network on the model is determined by the color coloration. Since during the day the intensity of passenger traffic changes, and the color of the sections of the city's route network in the model will also change depending on the number of vehicles on the stretch at a given time.

Thus, when conducting an experiment on the model, it is possible to determine the degree of congestion of the sections of the city's route network at each time period. In addition, the model allows you to change the initial parameters (bus schedule, type and number of vehicles on the route, routes themselves, bus speed, etc.) and analyze changes in the situation.

The results of the experiment on the simulation model give grounds for developing recommendations for optimizing the city's route network, for changing some routes for urban passenger transport, in order to bypass the most congested sections. In addition, such an analysis is aimed at improving the quality of the city's transport system by reducing the likelihood of accidents and eliminating the downtime of route vehicles due to congestion and traffic jams, and also contributes to the timely delivery of passengers.

Analysis of the results of the simulation experiment indicates that one of the central avenues of the city is overloaded, since the main part of the routes runs along this avenue. In order to study the possibility of unloading the specified section on the model, the intervals of bus movement along one of the routes were changed. It was found that this measure helps to reduce tension in the area under consideration. In addition, the analysis of the filling of vehicles and queues at stops showed that even with a reduction in the number of vehicles on the route, the transport needs of the population will be 
fully satisfied (the indicated changes in the model parameters led to a slight increase in the waiting time for a vehicle at a stop).

So, to summarize, we can say that the proposed model has the following advantages:

- The model of a real transport system is built on the basis of an object-oriented approach

- Visualization of the model allows you to easily identify the most congested sections of the city's transport network that require redistribution of traffic flows

\section{Conclusion}

Methods based on the determination of indicators that characterize the security of road users are used to assess the state of road safety. During the analysis of each method, the main positive and negative aspects were identified. Based on the results of theoretical studies, a scientific concept for reducing the number of road accidents was formulated, which is based on three conceptual provisions:

- On the representation of emergency situations in the form of a set of parameters and variables of the "driver-car-road-environment" system

- It is necessary to determine the "weighting coefficients" of the parameters and variables of the "driver-car-road-environment" system affecting the likelihood of an accident - it is necessary to conduct statistical monitoring of the parameters of the objects of the system "driver-car-roadenvironment" for adaptive traffic control in order to predict and accident prevention

Application of the developed model and analysis of data obtained as a result of an optimization experiment based on its use will improve the quality of transport services for the population, will help reduce tension on city roads and, as a result, reduce the number of accidents, and will also lead to an improvement in the environmental situation in some districts of the city.

In the future, this model can be improved by introducing into it information on the parameters of traffic flows of non-route vehicles (cars and other vehicles for individual use).

\section{References}

[1] R. V. L. Sokolin, Federal state statistics service, Education 45(5) (2008) 68-80.

[2] V. V. Golovko, V. I. Mayorov, V. S. Kurakov, Organization of the activities of the State Inspectorate for Road Safety, volume 1, TsOKR of the Ministry of Internal Affairs of Russia, Tomsk, Russia, 2009.

[3] A. N. Novikov, I. A. Novikov, Scientific and methodological approach to predicting and preventing road traffic accidents, Management of activities to ensure road safety: state, problems, ways of improvement 1 (2019) 336-342.

[4] D. Lord, F. Mannering, The statistical analysis of crash-frequency data: a review and assessment of methodological alternatives, Transportation research part A: policy and practice 44 (2010) 291305. doi:10.1016/j.tra.2010.02.001.

[5] F. L. Mannering, C. R. Bhat, Analytic methods in accident research: Methodological frontier and future directions, Analytic methods in accident research 1 (2014) 1-22. 10.1016/j.amar.2013.09.001.

[6] V. V. Semenov, Changing the paradigm in the theory of traffic flows, 1st. ed., Keldysh Institute preprints. MV Keldysh, Moscow, Russia, 2006.

[7] A. Yu. Krylatov, V. V. Zakharov, Management of transport flows in megalopolises, Flexibility and adaptability of global supply chains: Collection of articles of the Seventh Russian-German conference on logistics and SCM DR-LOG 5 (2012) 305-310.

[8] V. V. Semenov, Mathematical modeling of traffic flow at an unregulated intersection, Mathematical modeling 20 (2008) 543-550.

[9] K. F. Sergeeva, Analysis and optimization of traffic flows with the help of modeling, Site of the Intern. young. school-seminar "BICAMP: The Future of Informatics, Space, Aviation and Medical Instrumentation" 10 (2013) 64-108.

[10] V. E. Voronin, V. S. Kurantseva, Optimization of management of transport systems using simulation, IMMOD-2007 2 (2007) 42-46. 
[11] J. Barceló, E. Codina, J. Casas, J. L. Ferrer, D. García, Microscopic traffic simulation: A tool for the design, analysis and evaluation of intelligent transport systems, Journal of intelligent and robotic systems 41 (2005) 173-203. doi:10.1007/s10846-005-3808-2.

[12] J. De Cea, E. Fernández, Transit assignment for congested public transport systems: an equilibrium model, Transportation science 27 (1993) 133-147.

[13] L. S. Abramova, V. V. Shirin, G. G. Ptitsa, Analysis of methods for determining indicators of road safety, Bulletin of Kharkiv National Automobile and Road University 1 (2015) 118-123. 